\title{
Articles
}

\section{Cooperating Teachers' Roles and Responsibilities in a MATESOL Practicum}

\author{
Caroline Payant and John Murphy
}

Responding to a gap in relevant literatures, this study explores cooperating teachers' perceptions of their roles and responsibilities as contributors to the practicum experiences of preservice teachers of English as a second language who were pursuing a master's degree. Research tools featured focus group and individual interviews with 11 cooperating teachers who were working with practicum students. Findings include a perceived lack of communication between cooperating teachers and practicum course instructors, inadequate written descriptions of cooperating teachers' roles and responsibilities, missed opportunities to develop more fully the quality of cooperating teacher-practicum student collaborations, as well as cooperating teachers' recommendations for enhancing the practicum experiences of those involved.

Réagissant à une lacune dans la littérature connexe, cette étude se penche sur les perceptions qu'ont les enseignants coopérants de leurs rôles et responsabilités en tant qu'intervenants dans les stages d'étudiants à la maitrise, futurs enseignants de l'anglais langue seconde. Comme outils de recherche, nous avons eu recours aux groupes de consultation et aux entrevues individuelles avec onze enseignants coopérants qui travaillaient avec des stagiaires. Nous avons trouvé qu'il existe, entre autres, la perception d'un manque de communication entre les enseignants coopérants et les moniteurs de stage, des descriptions écrites inadéquates des rôles et responsabilités des enseignants coopérants, et des occasions ratées de poursuivre le développement de la qualité des collaborations entre les enseignants coopérants et les stagiaires. L'article évoque les recommandations par des enseignants coopérants visant l'amélioration des stages pour tous les intervenants.

\section{Introduction}

The second language (L2) teaching practicum is a core component in most Master's in the Teaching of English to Speakers of Other Languages (MATESOL) programs. During the mid-1990s, Palmer (1995) conducted a national survey and reported that two thirds of MATESOL programs in the United States included a required teaching practicum. Despite its popularity, the MATESOL practicum is both an under-theorized and under-explored re- 
search area (Crookes, 2003). To date, empirical studies have provided descriptions of MATESOL practicum models (Crookes; Flowerdew, 1999; Stoynoff, 1999), have explored practicum students' needs and perceptions of the practicum (Brinton \& Holten, 1989; Diaz-Greenberg \& Nevin, 2004; Hall Haley, 2004; Velez-Rendon, 2006), and have reported on practicum course instructors' beliefs about the practicum (Crookes; Richards \& Crookes, 1988). During the practicum, practicum students participate in the classroom of an experienced L2 teacher who is most commonly referred to as a cooperating teacher.

To date, however, only brief discussions reporting cooperating teachers' experiences are available, and few studies take their perspectives directly into account. For example, in response to perceived gaps in the available literature, Crookes (2003) published a book-long discussion about the design and implementation of MATESOL practicum courses. Although Crookes gives some attention to the importance of cooperating teachers' participation and collaboration between them and practicum students, he relegates the book's sole section on the process of working with a cooperating teacher to an appendix. In a more recent text, Richards and Farrell (2011) offer more sustained attention to the roles and responsibilities of practicum students and cooperating teachers and to the process of collaboration between them. Although their discussion stands as an important contribution, few research studies are cited in the text. We believe that to design successful practicum courses, more research-based information about the roles and contributions of each contributor to the practicum experience is needed.

In an effort to address this gap, in this study we explore how cooperating teachers understand their practicum-related roles and responsibilities. By focusing on cooperating teachers, our intention is to improve the preparation of current and prospective cooperating teachers in order to foster constructive working relationships between all parties who contribute to practicum experiences (i.e., language-learners, practicum students, practicum course instructors, and other cooperating teachers).

\section{Literature Review}

Practicum courses and other field-based experiences are key components of teacher preparation programs (Palmer, 1995; Richards \& Farrell, 2011). Practicum courses in particular are designed to encourage practicum students to reflect on and to participate in teaching-related activities under the supportive guidance of both a MATESOL seminar-based practicum course instructor and a language classroom-based cooperating teacher (Crookes, 2003). Cooperating teachers receive modest compensation for their efforts in some programs, although just as often their contributions are voluntary. Overall, the success of the field-based experiences made possible through a MATESOL practicum depends in large part on the practicum students' degree of engagement with opportunities to work with a cooperating teacher. 
The field of general education has a more extensive investigative tradition with respect to the roles played by cooperating teachers in the practicum, as well as a more sustained history of attention to the teaching practicum itself. Specific areas of investigation have focused on (a) exploring cooperating teachers' roles (Duquette, 1994; Ewart \& Straw, 2005; Koerner, 1992; Koskela \& Ganser, 1998); (b) identifying characteristics of successful cooperating teachers (Clarke, 2001); (c) documenting effective cooperating teachers' practices (Fairbanks, Freedman, \& Kahn, 2000; Graham, 2006; Kahn, 2001); (d) describing student teachers' and cooperating teachers' dynamics (Lemma, 1993; Veal \& Rikard, 1998); and (e) discussing the personal and professional benefits of working as a cooperating teacher (Applegate \& Lasley, 1982; Caruso, 1998; Sinclair, Dowson, \& Thistleton-Martin, 2006).

Findings from the field of general education provide valuable information for practicum course instructors with respect to potential cooperating teachers' contributions. However, MATESOL practicum course structures tend to differ from those featured in colleges of education. In the field of general education, student teachers fulfill teaching requirements at off-campus locations where they often assume full responsibilities as classroom teachers. In such programs, the practicum experience is intensive, and it may last for longer periods (e.g., a full academic year, Ewart \& Straw, 2005). Richards and Crookes (1988) conducted a survey of 120 US-based institutions to uncover the structures, practices, and goals of the MATESOL practicum. Their results indicated that the field-based practicum experiences offered by a large number of MATESOL programs featured the placement of practicum students with cooperating teachers who were teaching in English-as-a-second language (ESL) programs housed in the same university as the teacher preparation program. Also, MATESOL practicum experiences are typically conducted during a single academic semester, often the final semester of the candidates' graduate training. Finally, practicum students often participate in supervised teaching activities. In fact, unsupervised practicum student teaching experiences are short-lived and in some cases entirely absent. Although a few MATESOL programs offer more extensive practicum experiences requiring practicum students to teach for a whole semester or full academic year (Flowerdew, 1999; Phairee et al., 2008; Stoynoff, 1999), such programs are exceptions to the rule. In sum, there are clear differences between the practicum models of general education and those of MATESOL programs. These diverse structures affect the roles, potential contributions, and responsibilities of practicum students, practicum course instructors, and cooperating teachers in varied ways. Given such differences and lack of investigative attention, further research focusing on the roles of cooperating teachers affiliated with MATESOL programs is warranted.

The particular structures and contexts of the practicum course in MATESOL programs have motivated some earlier research. In one study, 
Farrell (2007a) documents his experience of working with Ho, a nonnative English-speaking (NNES) practicum student who had failed the practicum course the first time she was enrolled in it. The focus of Farrell's study was to report techniques for promoting reflective teaching practices from a practicum course instructor's perspective. Specifically, Farrell sought to probe the practicum student's tacit assumptions about L2 pedagogy. Working together, the researcher/practicum course instructor and student reformulated into maxims Ho's expectations about the practicum course. Through guided reflective practices, the practicum student came to realize that her teaching decisions and instructional practices were influenced primarily by personal L2 learning experiences and not by the L2 learning and teaching principles featured in the MATESOL program that she was attending.

In another study, Johnson (2003) explored the effects of working as a cooperating teacher with an NNES graduate student completing a MATESOL degree. As part of her exploration of the construction of her own identity as a cooperating teacher, Johnson discusses critical incidents that she experienced while mentoring this particular practicum student, who as well as being an NNES was also an observant Muslim. Johnson was surprised to observe that her ESL learners perceived the NNES practicum student as an English-language expert. This observation led Johnson to challenge what she subsequently came to perceive as her own inherited authority as an Englishlanguage expert. In her role as cooperating teacher, the incident prompted Johnson to reconsider her personal beliefs about the relative degrees of language-expert status of NNES and native English-speakers as teachers of English. In a second critical incident, Johnson recalled that during collaborative tasks, she was surprised to find that the practicum student was pairing male students together in order to preclude opportunities for men and women to work together. This grouping strategy made Johnson realize that personal beliefs surface in each instructional decision and that the practicum student's gender-centric grouping decisions conflicted with some of her own classroom teaching beliefs. Johnson explained that some of her language teacher's beliefs were responsive to issues of equality in the classroom and that in such circumstances, equality issues would have taken precedence over gender-related beliefs. For Johnson, the experience of working as a cooperating teacher prompted intense reflections about her own changing personal and professional identities.

Farrell (2007a) and Johnson (2003) demonstrate that each cultural and educational context offers unique experiences and challenges for cooperating teachers and practicum course instructors. However, to the best of our knowledge, no available literature reports on cooperating teachers' perspectives and beliefs about their roles in the MATESOL practicum. Therefore, we undertook an initial exploratory study in order to discover what were experienced cooperating teachers' perspectives and beliefs about the practicum 
and to understand better how cooperating teachers construe their roles while mentoring practicum students. The following research questions guided the qualitative research procedures that we implemented while working with a group of experienced cooperating teachers.

1. How do cooperating teachers experience the MATESOL practicum course?

2. What are cooperating teachers' roles and responsibilities during the MATESOL practicum course?

In the following section we discuss the context of the study, provide detailed descriptions of the format of the MATESOL teaching practicum, and introduce the focal cooperating teacher informants who participated in a series of research interviews.

\section{The Study}

\section{Context of the Practicum Course}

The study took place in a MATESOL program housed in a department of applied linguistics and ESL in a large research university in the southeast region of the US. The Intensive English Program (IEP), which focuses on teaching English for academic purposes (EAP) to postsecondary ESL learners, is a fully integrated unit in the same academic department. In this setting the MATESOL practicum consists of two major course components: (a) a twoand-a-half-hour weekly practicum seminar taught by a practicum course instructor; and (b) an ESL classroom-centered observation component made possible through access to the ESL/EAP courses offered by the department's IEP. Various members of the Department's faculty and doctoral students serve as practicum course instructors during each semester, one practicum course instructor per semester. For the ESL/EAP classroom-centered component, practicum students have access to one or more courses in the IEP. To meet the practicum's field-based component, individual practicum students are required to visit and observe 2.5 hours of class time per week in the context of either (a) a single IEP course spanning 12 weeks of a 14-week semester, or (b) two IEP courses for six weeks each over the same 12-week period. In this second option, one practicum student works with an initial cooperating teacher for six weeks in a single IEP course and then shifts to working with a second cooperating teacher and IEP course for the final six weeks of the semester. Some practicum students prefer working with one cooperating teacher for the 12-week period, whereas others prefer to participate in two separate IEP courses sequentially, thereby having opportunities to become closely acquainted with two cooperating teachers and two IEP courses rather than just one. Practicum course instructors differ on how they handle these alternative structures for involving practicum students in practicum fieldbased experiences. Some leave it to individual practicum students to elect an 
option for themselves, whereas others are more direct in assigning individual practicum students to one or the other observation structure. Whichever observation structure is in play (i.e., either 12 weeks with a single CT or two sequential six-week periods with two cooperating teachers), the preferred trajectory is for a practicum student's degree of active participation in a cooperating teacher's course to increase gradually over time. For example, during the first two weeks of IEP course participation, practicum students begin as classroom observers only. Following Day (1990), their observation tasks are supported and guided through the practicum course instructor's suggestions and seminar readings (Farrell, 2007b; Richards \& Lockhart, 1996; Wajnryb, 1990). When possible, practicum students are encouraged to discuss their observations with their respective cooperating teachers. Practicum students also complete written observation reports, which are later shared with the practicum course instructor and at times with the cooperating teacher. Following this initial period of classroom observation, a practicum student begins to take on a more participant-observer role. Here he or she begins to work with learners in contexts of one-on-one and small-group interactions during in-class group activities. In the fifth or sixth week, the practicum student is expected to lead at least one 20-25-minute practice teaching segment of a day's lesson while the cooperating teacher observes. As can be seen, in this structure the opportunity to practice-teach in front of a group of IEP learners constitutes a relatively minor portion of the practicum student's role. Rather, the practicum foregrounds professional development opportunities through guided observations and supported reflective practices focused on IEP teaching and learning. Some practicum students who decide to continue with a single cooperating teacher for the more extended 12-week period may have more opportunities to practice-teach. Through these practices, they are afforded opportunities to integrate the wealth and breadth of disciplinary knowledge focused on as part of their graduate studies (Grabe, Stoller, \& Tardy, 2000).

\section{Participants and Data Collection}

Data for the study were collected over the 2008-2009 academic year. During fall 2008, a total of 11 cooperating teachers participated in one of two 75minute focus-group interviews conducted by the first author. Barbour and Schostak (2005) suggest that focus group interviews "provide insights into the formation of views which are less likely to be revealed during individual interviews" (p. 45). Following the focus-group interviews, three of the 11 cooperating teacher participants were recruited to participate in a series of individual interviews. At the time of the study, all the individual-interview cooperating teachers were working with a practicum student, and each had previous experiences as a practicum student, cooperating teacher, and/or practicum course instructor. The first individual-interview cooperating 
teacher, Rachel, had previously earned a MATESOL degree from the same department in which the study took place. At the time of the study, she had four years of IEP teaching experience and had previously served as a CT for seven practicum students. Thus Rachel was able to discuss her experiences from two insider perspectives: as a practicum student who had worked with a cooperating teacher in the same MATESOL program, and more recently as a cooperating teacher for multiple semesters. The second individual-interview cooperating teacher, Angela, had more than 35 years of teaching experience, had 10 years of IEP teaching experience, and had previously served as a practicum course instructor in the same department. In addition, Angela had a long history of serving as a cooperating teacher with numerous practicum students. The third individual-interview cooperating teacher, Danielle, had five years of IEP teaching experience in the department and had supervised many MATESOL students in her role as coordinator of the department's IEP tutoring program. Danielle had earned her MATESOL degree from another university that did not offer a structured practicum course. Rather, as part of her master's-level training, Danielle had participated in unsupervised teaching experiences in nearby community centers. Thus her beliefs about the cooperating teacher's role had been shaped by her five years of working as a cooperating teacher and as the tutoring coordinator. Each of the three individual-interview cooperating teachers participated in three 4560-minute semistructured interviews in addition to the earlier focus-group interview. The range of their experiences was fortuitous as they offered multiple perspectives on the research questions.

\section{Data Analysis}

As is typical in qualitative research, data collection and analysis processes interacted continually. For example, adoption of iterative procedures made it possible to devise and later refine guiding questions for subsequent interviews. These efforts also facilitated ongoing reflection on emerging themes. Once recorded, all the interviews were transcribed verbatim. Then each transcript was read recursively multiple times over an extended period. Key words and key sentences were placed in transcript page margins, and eventually data analysis codes were created. As part of the iterative process, recurring ideas were grouped together. Eventually, seven overarching themes emerged from the interview data. These were:

1. Structure and design of the practicum course;

2. Role of a cooperating teacher;

3. Qualities of a cooperating teacher;

4. Benefits for a cooperating teacher;

5. Role of a practicum student;

6. Qualities of a practicum student; and

7. Ideas to improve cooperating teacher-practicum student relationships. 
While we continued to examine the data, subcategories were identified in each of these seven larger themes; transcripts and codes were shared and discussed with other specialists; and preliminary findings were presented and discussed as part of a local, departmental presentation. It is worth mentioning that several of the cooperating teachers who participated in the study attended and contributed to the discussion phase of the departmental presentation. Although the cooperating teachers present agreed with the other findings reported, they said that one theme did not ring true. There had been an eighth theme in addition to the seven listed above, namely, the role of cooperating teachers as gatekeepers to the wider profession of ESL teaching. When the cooperating teachers attending the departmental presentation explained that the gatekeeping role did not seem representative of their experiences, it was dropped from the research report. Because the research reported here focuses on cooperating teachers' roles and understandings, in the following section we focus on the second, third, and seventh of the themes listed above.

\section{Results and Discussion}

\section{Success of the Practicum}

As a required graduate course leading to the MATESOL degree, practicum students and the practicum course instructor meet for two and a half hours weekly in the practicum seminar. There practicum students discuss assigned readings that focus on topics such as classroom observation procedures, teachers' decision-making, classroom management, reflective teaching, and pathways for long-term professional development. In addition, course participants share insights from their IEP classroom observation experiences. Therefore, the quality and nature of practicum students' practicum experiences in large part are contingent on the quality and nature of collaborative relationships that develop between practicum students, their respective cooperating teachers, and the course instructor. Practicum students are in somewhat privileged positions because they have many opportunities to communicate with two mentor types (a cooperating teacher and the practicum course instructor) as well as with their practicum classmates. However, a central theme that emerged from the data is the cooperating teachers' shared belief that communications between cooperating teachers and practicum course instructors are sorely underdeveloped. In fact, cooperating teachers lament that communications between the practicum course instructor and individual CTs are not only infrequent, but usually occur only twice during the observation period. The first contact is made near the start of the semester (in person or via e-mail) as the practicum course instructor is trying to recruit as many cooperating teachers as will be needed. At this time, the practicum course instructor inquires about cooperating teachers' 
availability and willingness to serve the MATESOL program in this capacity. If a cooperating teacher expresses interest, soon thereafter he or she receives an e-mail with the practicum student's name, some descriptive information on the format and duration of expectations for the IEP classroom component of the practicum, a listing of typical practicum students' tasks and responsibilities, and additional suggestions for involving the student in one of the cooperating teacher's IEP courses. Cooperating teachers report that details relevant to their specific roles and responsibilities are poorly defined. As revealed in the interview data, cooperating teachers believe that these initial practicum course instructors' communications consist of little more than broad recommendations, which most of the participating cooperating teachers characterized as inadequate. They offered several explanations for why more detailed specifications of cooperating teachers' roles and responsibilities were not available. They surmised, for example, that a practicum course instructor might be trying to avoid imposing particular expectations with the intention of leaving room for individual cooperating teachers to explore their own ways of working with practicum students. By way of illustration, an initial e-mail communication disseminated by one practicum course instructor featured several mitigation phrases (e.g., "you may involve," "as you wish," and "you, the cooperating teacher, would decide the role that the practicum student would play"). Unfortunately, as revealed in the interview data, a number of cooperating teachers mentioned that even after serving in this capacity for several semesters, they continued to lack a clear understanding of their cooperating teacher's roles and responsibilities. To illustrate a shared sentiment, one of the cooperating teachers from the focus group complained, "The [practicum course instructor] assumes that the CT knows what their role is, but nobody tells us what we need to do."

As revealed through both the focus group and individual interviews, cooperating teachers find their own ways of constructing fuller and more personalized understandings of their roles and responsibilities by (a) consulting with other more experienced cooperating teachers; (b) drawing on their experiences of once having been a practicum student in the practicum course; (c) reflecting on previous experience of having served as a cooperating teacher, and in the case of one cooperating teacher, (d) reflecting on previous experiences of having served as a practicum course instructor herself. One of the clearest findings from the data is that cooperating teachers would like to be more fully informed about the MATESOL program's and practicum course instructors' expectations for the role of a cooperating teacher. A related issue identified is that cooperating teachers believe that practicum course instructors should more closely monitor the quality of cooperating teacherpracticum student interactions and collaborations.

Through their practicum experiences over several years, cooperating teachers noticed that practicum course instructors sometimes sent a second 
e-mail (e.g., mid-semester) if some sort of problem had come to the practicum course instructor's attention. However, all the cooperating teachers agreed that more frequent communications and other contacts between cooperating teachers and the practicum course instructor were needed. One of the less experienced cooperating teachers from the focus group expressed her concerns as follows: "If a practicum student is disruptive, I guess I don't know what I would do. You know, what do I say? Do I have a disciplinary conversation with the [practicum] student, or do I take that to the practicum [course] instructor?" Unsure what to do, cooperating teachers believe that before the start of the practicum they should be brought into more substantive discussions about such scenarios, including possible ways of working through them. However, several cooperating teachers also explained that problematic situations were far from the only reasons for developing more open communications. On this theme, cooperating teachers explained that they needed to know that the practicum course instructor would be available to support them as needed. Rachel expressed her desire for practicum course instructors to:

really [just] check-in [every now and then] and see, like, what the interaction is like, how often you're meeting with the practicum student, or some way to see like what [my] dynamic [with the practicum student] is like. This semester, I wouldn't have minded that, 'cause I feel like I have had no interaction with my practicum student and I don't really know what to do to make [the quality of our relationship] any better.

Finally, after having opened their classrooms to practicum students for six or 12 weeks as part of practicum student assessment procedures, cooperating teachers receive a rubric by which they are asked to assess their particular practicum students' overall performance. During the interviews, several cooperating teachers questioned why their assessment was valued at a mere $10 \%$ of the practicum student's final practicum course grade. Some believed that because they worked closely with practicum students for extended periods, their assessments of the quality of the students' efforts merited considerably more than $10 \%$ of a their final grade.

Data analysis reveals that cooperating teachers value communication and want their voices to be heard in ways signaling that they are being recognized as essential contributors to practicum students' learner-of-teaching experiences. Cooperating teachers proposed specific means for practicum course instructors to build and maintain closer communications with cooperating teachers, including one or more orientation meetings early in the semester, periodic office visits, e-mail exchanges, and brown-bag discussions and workshops. Cooperating teachers explained that the respective roles played by CTs and practicum course instructors needed to be more closely aligned in order to permit better coordination in the professional shaping of 
practicum students' learning-of-teaching experiences. As one participant explained, "The CT is cooperating with both the [practicum course instructor] and also [with] the practicum student in order to make the learning experience more enriching." In particular, cooperating teachers wish to be clearly informed about their roles during the classroom observation component of the practicum. In the following section we discuss how cooperating teachers define their roles in the practicum context.

\section{Cooperating Teachers' Roles and Behaviors}

As mentioned above, cooperating teachers seek development of a process that will enhance the quality and frequency of communications between practicum course instructors and themselves. As a requisite platform from which processes and procedures for enhanced communications may emerge, cooperating teachers call for clearer descriptions and illustrations of their roles and responsibilities. As a starting point, the following section presents findings related to cooperating teachers' own perceptions of the various roles they play and how these roles change over time in the various stages of the practicum. Labels for the four cooperating teachers' roles indentified from the data are: communicator, demystifier, catalyst for identity shifts, and mentor.

\section{Communicator}

Cooperating teachers sometimes find that having an observer in the classroom can be intimidating or even disruptive. However, more often than not, they explain that practicum students seem completely unaware of the potential for such complications. Cooperating teachers realize that in an effort to raise practicum students' awareness of what it means to be a sensitive and respectful observer, the seminar component of the practicum features several required readings that provide opportunities to discuss themes of classroom observation etiquette (Murphy, 1992; Richards \& Farrell, 2011). However, although aware that the seminar featured such discussion, the cooperating teachers were concerned that each of them was unique with respect to what he or she would consider appropriate or inappropriate practicum students' behaviors. Cooperating teachers were clear in their belief that each relationship developing between them and a practicum student was unique and open to subtle modifications perhaps best explored through direct communication and negotiation. However, cooperating teachers also expressed the following conundrum: they want practicum students to feel welcome, but the cooperating teachers also want to be clear about what they consider acceptable and unacceptable practicum students' classroom behaviors. One of their apprehensions is that discussing impermissible and/or problematic classroom behaviors with a practicum student may hinder the development of a mutually constructive and positive working relationship. Cooperating teachers differed on how best to resolve this conundrum. Possible resolutions 
mentioned called for cooperating teachers to: (a) make themselves available to meet with the practicum student before in-class observations begin and to use such opportunities to discuss directly personal preferences and concerns; (b) e-mail the practicum student in anticipation of such an initial faceto-face meeting and include a preliminary listing of the cooperating teacher's personal preferences and concerns, which could then be discussed and clarified when he or she and the practicum student first meet; (c) share personal preferences and concerns with the practicum course instructor, who in turn would discuss these with the relevant practicum student before the start of classroom observations; (d) share their preferences and concerns with the practicum course instructor, but ask him or her to discuss the issues more generically in the context of a whole-class seminar conversation without referring to any particular cooperating teacher. Cooperating teachers explained that a benefit of clarifying their preferences early is that increased clarity serves to establish a foundation for healthy relationships among all parties involved in the practicum process.

In addition to discussing themes of classroom observation etiquette, cooperating teachers also mentioned that pre-observation communications with practicum students can serve not only to clarify what cooperating teachers expect from practicum students, but also how their respective role(s) may shift over time. In this context, a general expectation at the start of the practicum is that a practicum student will begin in an observer's role and then gradually transition to more of a participant-observer's role after several weeks. Although cooperating teachers were careful to explain that the following is not possible for every practicum student, most are eventually able to take on a short-term practice-teaching role in the cooperating teacher's classroom. However, cooperating teachers characterized the reality of how such transitions unfold as inherently complex and difficult to predict. Such transitions depend on the degree of confidence and trust that develops within the six- or 12-week observation periods. It is also worth mentioning that the process is viewed variably by individual cooperating teachers. For example, one experienced cooperating teacher preferred a practicum student to transition quickly from observer to more of a participant-observer's role. As Danielle explained, "If they're [going to practice-]teach, I want them to jump in sooner [rather] than later to start establishing rapport [with IEP learners]." On the other hand, Nathan, a cooperating teacher from the focus group, preferred that practicum students continue in the observer's role for longer. He further explained that any student who worked with him should not assume that he or she would automatically reach the stage of a more active role. For example, Nathan looked for signs that the practicum student had a clear grasp of the goals and purposes of the IEP course and was familiar and able to work appropriately with course materials. In the context of the relatively high-stakes IEP courses he teaches, Nathan explained that the 
needs of IEP learners must always come first and that he had to keep IEP learners' best interests firmly in mind. In the interview he articulated a convincing case that he needed both to assume and to retain responsibility for deciding whether a practicum student could begin to take on a more active practice-teaching role in the relatively high-stakes IEP courses that he taught. His comments suggested that although cooperating teachers might find consultations with the practicum student and practicum course instructor useful and sometimes necessary, cooperating teachers needed to know that they were supported by an administrative structure through which they retained responsibility for making these important decisions regardless of the stated expectations of the practicum seminar.

In sum, a clear theme revealed in the data is how important it is for a cooperating teacher to be an effective communicator with both the practicum student and the practicum course instructor as to how the practicum student's ESL classroom experiences are most likely to unfold. By clarifying expectations at the start of the cooperating teacher-practicum student connection, the students will have clearer understandings of what their particular cooperating teacher expects, as well as how the pacing and sequencing of his or her expectations may change over time (i.e., more quickly for cooperating teacher-Danielle, more gradually for cooperating teacherNathan). Cooperating teacher informants described their role as that of a proactive communicator as necessarily ongoing, so that once a practicum student became involved in the IEP course, other potential practicum students' roles and responsibilities might emerge, as long as they were being supported and guided by the cooperating teacher.

\section{Demystifier}

The focus group and individual interviews suggest that experienced teachers are great illusionists in the sense that cooperating teachers' classroom behaviors sometimes leave practicum students with the impression that acts of teaching are simple or even effortless. Even when unintended, such masking of some of the complexities underlying teaching can make it difficult for inexperienced learners-of-teaching to recognize some of the tacit or unobservable forms of knowledge that cooperating teachers possess. Therefore, cooperating teachers have the potential to serve as demystifiers, making the invisible visible, and clarifying procedures and processes for the benefit of practicum students.

Lesson-planning is an example of a less visible dimension of teaching of which practicum students are often unaware. Angela, with 10 years of experience as a cooperating teacher, initially assumed that practicum students would already know how much time and energy went into preparing an IEP lesson. However, it was only recently, while working as a cooperating teacher with an inexperienced practicum student, that she came to realize that 
practicum students had little awareness of what happens before the lesson starts. She explained, "It's not always obvious to an outsider how much preparation goes into things and how long things take to prepare." So unless they are planning for and teaching a class, practicum students may remain unaware of the demands involved in creating a lesson plan and the reflective processes that underpin acts of lesson-planning. Although cooperating teachers explain that they try to share lesson plans with practicum students before a given class, this practice may fall short of having much effect on a practicum student's developing knowledge base. Rachel explained that years earlier, while she was still in the role of a practicum student, one of her practicum classmates mentioned how much she had appreciated the opportunity to sit next to and witness first-hand the classmate's cooperating teacher's preparation of an upcoming lesson. Rachel recalled that her classmate reported on the incredible benefits of such shadowing of a cooperating teacher's planning-in-action. Several cooperating teachers talked about the potential benefits of inviting a practicum student to participate in planning a lesson, particularly if such involvement could occur during the initial weeks of a semester before practicum students had to plan lessons for their practice-teaching opportunities. These cooperating teachers believe that a participatory opportunity of this nature may have a more profound effect on the development of a practicum student's pedagogical knowledge than merely an explanation of how one went about the lesson-planning process after the fact. By observing the planning of a lesson in action, previously inaccessible processes can be rendered more transparent. A later stage might culminate with the cooperating teacher and practicum student collaborating in planning one of the practicum student's own practice-teaching lessons. In sum, cooperating teachers can structure such activities as transitional stages that progress from face-to-face interactions centered on their making the invisible more transparent, to collaborative lesson-planning, to more autonomous practicum students' lesson planning practices. Raising practicum students' awareness and increasing their participation in the lesson-planning process can support them in learning to recognize some of the less transparent dimensions of language-teaching.

Two other areas generally less visible to practicum students are a teacher's practical knowledge base and practices of reflective teaching. Cooperating teacher informants explained that they must be generous in sharing insights about teaching with practicum students. Rachel proposed that they do their best to try "[to be] there to kind of dissect a class ... the components of a class." Through opportunities to work with cooperating teachers who are conscientious in trying to make things as transparent as possible, practicum students are more likely to notice the more subtle dimensions of classroom events and may deepen their abilities to notice, ask about, and reflect on less observable dimensions of teaching. For such learning-about-teaching oppor- 
tunities to emerge, the cooperating teacher and practicum student must work together to arrange meeting times and to develop mutually supportive collaborative procedures. A possible arrangement mentioned by one experienced cooperating teacher would be to include pre-observation time to work together before a given class (e.g., when he or she would have a chance to discuss the lesson-planning process and desired outcomes) and a subsequent post-observation meeting to discuss unplanned outcomes and what might have been some of the instructional decisions made by the cooperating teacher while operating live in the classroom. In short, an observation cycle for a single class that includes both pre-lesson and post-lesson opportunities for building awareness, discussion, and reflection may constitute an even more promising direction for cooperative teacher-practicum student collaboration than more traditional models of multiple post-observation meetings.

\section{Catalyst for Identity Shifts}

Once in-class observations are underway and practicum students have a better appreciation for the kinds of thinking and planning that engage teachers before a lesson, cooperating teachers expect practicum students to adopt a more active role in the classroom. To make the transition from observer to participant-observer, cooperating teachers must provide support while practicum students begin to re-imagine their own identities as shifting from one of an observer-of-teaching to one more closely approximating a classroom teacher. While witnessing such transformations, cooperating teachers explain that they look for evidence that practicum students are starting to reimagine their identities and responsibilities. Some signs are that the practicum student is showing initiative by being consistent in arriving to class a few minutes early, being attentive during the entire class, responding appropriately to the cooperating teacher's in-class cues, asking him or her interesting questions about the course, expressing curiosity about course materials, seeking opportunities to meet with the cooperating teacher outside class, sharing and discussing personal insights, and/or sharing and discussing observation notes. Such proactive actions and behaviors serve to motivate a cooperating teacher to invite practicum students to assume an increasingly more responsible role. At this stage, cooperating teachers encourage them to begin to listen in on small-group work for particular purposes (e.g., to identify learners' confusions with pedagogic tasks, to document learners' needs), to monitor learner dyads and small groups more closely, and to assist with small-group work throughout the classroom. Danielle believes that it is important to inform and remind practicum students that they need to grow beyond merely perceiving themselves as MATESOL students. Rather, she tries to build their self-confidence while encouraging them to assume more active roles as in-class tutors and discussion facilitators. She explains that when practicum students are serving facilitative 
roles in a cooperating teacher's class, "[practicum students] aren't [there] to give the answers, they're there to kind of prompt answers, and to facilitate [IEP students'] discussion." Similarly, Rachel believes that practicum students should be encouraged to grow toward more of a teaching role and away from the observer role, a natural progression that Rachel finds that many practicum students resist. By carefully and explicitly socializing practicum students into fuller classroom leadership roles, cooperating teachers are better able to facilitate the practicum students' much-needed identity shift from learner-of-teaching to one that includes classroom teacher. Such experiences are more likely to build practicum students' confidence as they enter the next and final stage of the practicum: practice-teaching.

\section{Mentor}

In the MATESOL program that we studied, the practicum experience culminates with the implementation of one or two 20-25-minute practice-teaching opportunities in the cooperating teacher's class. To determine what a practicum student will do, a cooperating teacher advises, guides, and in other ways supports the practicum student's efforts. At this stage, cooperating teacher informants describe the process of collaboration as encompassing three phases: collaborative development of what the practicum student is going to teach; opportunity for the practicum student to practice-teach solo while implementing the planned lesson segment; and collaborative post-reflection and follow-up discussion.

In the initial phase of lesson development, a cooperating teacher tries to reduce predictable degrees of practicum students' anxiety by suggesting course topics with which he or she will feel comfortable and be capable of teaching. Next the cooperating teacher and practicum student begin to negotiate the content and plans for practice-teaching. Typically, the cooperating teacher shares relevant materials, and the practicum student and cooperating teacher exchange drafts of the lesson plan. During these preparation stages, cooperating teachers say that they find themselves working hard to avoid natural impulses to prescribe directly what the practicum student should and should not do. Rather, throughout the process, they try to encourage the practicum student to think and plan reflectively by asking relevant questions intended to build awareness of how best to meet IEP learners' needs. For example, Angela explains that she prioritizes reflection and discussion about classroom management issues (e.g., timing, pacing, sequencing, giving directions) and how best to maximize IEP learners' participation. Cooperating teachers support practicum students' efforts in various ways during these preparation stages face-to-face, by telephone, and/or by e-mail.

Once a practicum student's plans for teaching are sufficiently developed, Danielle likes to review the lesson plan with him or her in person while trying to help him or her to anticipate possible complications, predictable ques- 
tions, and learners' difficulties. This process promotes anticipatory reflective practices (Conway, 2001) and simultaneously serves to reduce anxiety. The day a practicum student actually practice-teaches, most of the cooperating teacher informants say they prefer to let IEP language-learners know at the start of the class that the practicum student will be taking over for a substantial part of the lesson. To reduce potential confusion among IEP students, Angela adds that she tries to make clear connections and a smooth transition between both teachers' contributions that day. While the practicum student is practice-teaching, cooperating teachers explain that they serve more of an observer-of-teaching role. Most focus on taking careful descriptive notes with the intention of trying to emphasize things that are going well. They also keep note of at least a few areas for possible improvement. At such times, they explain that they wish to be as supportive as possible to foster the practicum student's teaching confidence and to facilitate independent decision-making. Later that day or within a few days, a cooperating teacher shares his or her observation notes with the practicum student and arranges for a time to discuss strengths, areas for teaching improvement, and modifications for future implementation. Although the interviews featured little discussion of specific reflection-on-teaching practices (Farrell, 2007b) a postpractice-teaching meeting would seem an ideal opportunity for cooperating teachers to foster such practices. Here practicum students and cooperating teachers can collaboratively reflect on and discuss some of what transpired during the practicum student's practice-teaching. By adopting contemporary L2 teacher development models such as Allwright's $(1992,2003)$ stance of exploratory practice, a cooperating teacher could work with the practicum student collaboratively to identify strengths and potential areas for improvement, explore alternative ways of teaching, discuss activity adaptations, and make plans for future teaching.

Over the span of either a six- or 12-week connection with a practicum student, cooperating teachers assume multiple roles that are multifaceted, dynamic, and evolve over time. The nature of their contributions continually shifts in response to changes in the perceived awareness, understanding, aspirations, and capabilities of practicum students. Juggling varied sets of responsibility simultaneously and bearing in mind that their concurrent responsibilities as IEP classroom teachers never abate, the role of cooperating teachers is demanding. Minimally, it calls for creativity, focused attention, and personal tact.

\section{Conclusion, Implications, and Future Directions}

Analysis of the interview data led to identification of unanticipated gaps in practicum course structures with respect to the need for more open communication and how best to define cooperating teachers' roles. An essential finding is the perceived lack of sufficient dialogue between practicum course 
instructors and cooperating teachers, both of whom are key players in the professional development of preservice teachers. With the intention of creating a more fully responsive and inclusive learning community, the cooperating teachers who participated in the study requested increased levels of practicum course instructor-cooperating teacher communications throughout all phases of the practicum. The study also illuminated some of the ways that cooperating teachers conceptualize their roles and responsibilities, particularly how they perceive these as shifting between communicator, demystifier, catalyst for identity change, and mentor. Although the four roles identified could be conceptualized as progressing in a linear manner, future research might explore some of the more subtle ways that such roles interrelate, blend, and overlap. Grounded by what we learned during data analysis, our intuition suggests that for cooperating teacher-practicum student relationships to function well, the roles that a cooperating teacher manifests must be sensitive to situational conditions in response to practicum students' needs at particular times. The arc of cooperating teachers' roles is all the more complex because they continue to serve as IEP classroom teachers even while doing their best to mentor practicum students. As evidenced in the interview data, the role of classroom language teacher is one that all the cooperating teacher informants showed every sign of prioritizing as foremost among their many competing responsibilities.

We were fascinated to learn that the voices of the interviewed cooperating teachers echoed a core controversy that occupies considerable attention in contemporary L2 teacher development literature. As initially proposed by Freeman and Johnson (1998), subsequently critiqued by Yates and Muchisky (2003), Muchisky and Yates (2004), and Tarone and Allwright (2005), and further clarified and expanded in Freeman and Johnson $(2004,2005)$, the controversy is about the question, What constitutes the knowledge base of L2 teaching? For practicum course instructors, cooperating teachers, and L2 teacher educators in general, few questions are more directly relevant to our professional activities. Responses have resulted in two currents of thought. In MATESOL programs, the currents sometimes flow parallel with limited overlap opportunity, or they sometimes diverge widely, although an increasing number of programs seem successful in shaping the landscape of teacher development activity to allow the currents to flow in confluence (Gebhard, 1998). The first current foregrounds what historically has been perceived as "the academic underpinnings of classroom skills," whereas the second foregrounds attention to "classroom teaching skills and pedagogic issues" (Richards, 2008, p. 5). The former includes topics in applied linguistics such as syntax, morphology, phonology, second-language acquisition, corpus linguistics, sociolinguistics, and so forth. At least in North America, curriculum structures in most MATESOL programs devote in-depth attention to such topics through separate seminar courses (Grabe et al., 2000; Kornblum \& 
Garschick, 2001; Palmer, 1995). This trend perhaps reflects a common assumption that once preservice teachers have sufficient knowledge of relevant academic topics and have completed a practicum course, they are ready to begin their L2 teaching careers. In contrast, the second current foregrounds efforts to understand more clearly teachers' cognitions, classroom teaching skills, and related pedagogic issues (e.g., action system knowledge, classroom management, pedagogical content knowledge). These are notoriously difficult to teach directly and/or learn effectively in seminar settings (Bartels, 2009). This second current is probably best known in MATESOL circles through Johnson's $(2006,2009)$ discussions of a "sociocultural turn" in understandings of L2 teachers' development. Extending themes closely aligned with Vygotsky $(1978,1986)$, specialists who work in a sociocultural tradition view learning as a mediated and negotiated process that occurs in the learner's zone of proximal development (ZPD). As initially proposed in connection with the cognitive development of children, a learner's ZPD is "the distance between the actual developmental level as determined by independent problem solving and the level of potential development as determined though problem solving under adult guidance or in collaboration with more capable peers" (Vygotsky, 1978, p. 86). When applied to the experiences of practicum students, the process of learning to teach may be conceptualized as a socially and culturally constituted endeavor (Richards, 2008) through which the professional development of novice teachers depends on guided opportunities to interact with, to be mentored by, and to learn while working alongside more experienced teachers.

As researchers and L2 teacher educators, we were both encouraged and somewhat surprised to find connections to these broad teacher development themes in the interviews with cooperating teachers. In MATESOL programs such as that described here, the practicum is the primary opportunity for graduate student learners-of-teaching to participate in sustained, substantive conversations with more experienced classroom teachers. Their conversations are all the more likely to be substantive because each cooperating teacher-practicum student pair has multiple opportunities to engage in meaningful discussions of classroom realities. It is important to note that the discussions are grounded in the immediate context of the cooperating teacher's course as well as in the broader language program in which the cooperating teacher is operating. If handled well, these opportunities meet requisite conditions for the growth and development of novice teachers, changes that can best be studied from a sociocultural perspective. As evidence, the cooperating teachers interviewed in the study recognized that their connections with practicum students were rich in teacher development potential, and they were explicit in saying that they would prefer such potential to be even more fully realized and refined. Our analysis of the interview transcripts reveals the cooperating teachers as well aware of learning-to-teach 
potentials that their mentoring contributions services made possible. For example, cooperating teachers' descriptions of how they work to engender learner-of-teaching development revealed sufficient scaffolding support for practicum students to be gradually challenged to assume more responsibilities inside and outside the classroom. By asking for (a) clearer descriptions of their practicum-related roles and responsibilities, and (b) more sustained support and collaboration from practicum course instructors, the cooperating teacher participants seem well positioned to enhance L2 teacher development efforts in the MATESOL practicum. At the same time, cooperating teachers voiced frustration that their efforts remain under-appreciated and under-used. A possible explanation is that some of the practicum course instructors with whom the study's cooperating teachers were interacting had yet to integrate fully the implications of sociocultural theory or other constructivist models in connection with teacher development practices in the practicum course. It is also possible that conventional curriculum structures of many MATESOL programs may hinder fuller inclusion of cooperating teachers' voices and contributions in a single-semester practicum context. Future training for cooperating teachers may benefit from discussions of how more experienced teachers can contribute to language-teachers' development from a sociocultural perspective.

Given the complexity of cooperating teacher-practicum student relationships discussed in this report, it would be naïve for anyone involved in the practicum to assume that a competent language teacher will automatically be able to serve as an effective cooperating teacher. Although there is a long history of classroom teachers who generously step up and demonstrate that they are fully capable of learning to serve well in this capacity, appropriate training, professional support, and time dedicated to exploring and developing the requisite competences seem warranted. As a necessary first step, it is essential for cooperating teachers to be better informed about the multiple roles that they will need to play and the competences that they will need to develop in order to serve effectively. As support for becoming better informed, practicum course instructors and cooperating teachers may find teacher-development resources such as Bailey (2006) and Richards and Farrell (2011) to be useful. However, to the best of our knowledge, this study is the first investigative effort from within the TESOL tradition to document cooperating teachers' roles and responsibilities by examining their own perspectives. One limitation of the study is that we were able to work with only 11 cooperating teachers from a single program and that only three of these were interviewed individually. It will be interesting to see if the findings reported here are shared by a larger number of cooperating teachers across additional programs. Because this was an initial study employing qualitative investigative procedures, subsequent research, both qualitative and quantitative in nature, is needed. On this theme, we find compelling Johnson and 
Golombek's (2011) recent call for the inclusion of narrative inquiry as a tool for "knowledge-building" and generating more efficient "professional development practices" (p. 486). Although we decided to investigate cooperating teachers' perspectives because their voices were under-represented in the current literature, subsequent explorations may find ways to include the perspectives of practicum students, practicum course instructors, and languagelearners as well. We trust that this investigation provides convincing evidence that cooperating teachers' contributions represent a valuable set of sociocultural resources that practicum course instructors and other L2 teacher educators would be wise exploit more efficiently, particularly through closer collaboration between cooperating teachers and practicum course instructors. Finally, we would be remiss not to acknowledge that financial compensation for the time and energy that an already busy classroom teacher will need to devote to the cooperating teacher role seems warranted. Our impression is that in MATESOL programs such as the one in this study, practicum course instructors have barely begun to scratch the surface of what cooperating teachers' contributions to the professional development of practicum student might one day become.

\section{Acknowledgments}

We thank the dedicated cooperating teachers who provided invaluable insights throughout the study. We also thank Diane Belcher, who encouraged and supported this research project. Also, we thank the anonymous reviewers for their constructive comments and feedback.

\section{The Authors}

Caroline Payant is an assistant professor of applied linguistics in the Department of English at the University of Idaho. Her areas of interest include multilingual acquisition, task-based language teaching, classroom-based research, and teacher education. Caroline has a range of experience in teaching TESOL/Applied Linguistic courses and French, Spanish, and English courses.

John Murphy is a professor of applied linguistics and ESL at Georgia State University. His research interests include second-language (L2) teacher development; approaches to L2 instruction; and the teaching of L2 listening, speaking, and pronunciation. He is co-editor of the MATESOL methods text Understanding the Course We Teach: Local Perspective on English Language Teaching (2001, University of Michigan Press).

\section{References}

Allwright, D. (1992). Exploratory teaching: Bringing research and pedagogy together in the language classroom. Revue de Phonétique Appliquée, 103-104, 101-117.

Allwright, D. (2003). Exploratory practice: Rethinking practitioner research in language teaching. Language Teaching Research, 7(2), 113-141.

Applegate, J.H., \& Lasley, T.J. (1982). Cooperating teachers' problems with preservice field experience students. Journal of Teacher Education, 33(2), 15-18.

Barbour, R.S., \& Schostak, J. (2005). Interviewing and focus groups. In B. Somekh \& C. Lewin (Eds.), Research methods in the social sciences (pp. 41-48). London: Sage.

Bailey, K.M. (2006). Language teacher supervision: A casebook of critical incidents. New York: Cambridge University Press. 
Bartels, N. (2009). Knowledge about language. In A. Burns \& J.C. Richards (Eds.), The Cambridge guide to second language teacher education (pp. 125-134). New York: Cambridge University Press.

Brinton, D., \& Holten, C. (1989). What novice teachers focus on: The practicum in TESL. TESOL Quarterly, 23, 343-350.

Caruso, J.J. (1998). What cooperating teacher case studies reveal about their phases of development as supervisors of student teachers. European Journal of Teacher Education, 21(1), 119-132.

Clarke, A. (2001). Characteristics of co-operating teachers. Canadian Journal of Education, 26, 237-256.

Conway, P.F. (2001). Anticipatory reflection while learning to teach: From a temporally truncated to a temporally distributed model of reflection in teacher education. Teaching and Teacher Education, 17(1), 89-106.

Crookes, G. (2003). A practicum in TESOL: Professional development through teaching practice. Cambridge, UK: Cambridge University Press.

Day, R.R. (1990). Teacher observation in second language teacher education. In J.C. Richards \& D. Nunan (Eds.), Second language teacher education (pp. 43-61). London: Cambridge University Press.

Diaz-Greenberg, R., \& Nevin, A. (2004). Listen to the voices of foreign language student teachers: Implications for foreign language educators. In A. Phipps \& M. Guilherme (Eds.), Critical pedagogy: Political approaches to language and intercultural communication. Clevedon, UK: Multilingual Matters.

Duquette, C. (1994). The role of the cooperating teacher in a school-based teacher education program: Benefits and concerns. Teaching and Teacher Education, 10, 345-353.

Ewart, G., \& Straw, S.B. (2005). A seven-month practicum: Collaborating teachers' response. Canadian Journal of Education, 28, 185-202.

Fairbanks, C.M., Freedman, D., \& Kahn, C. (2000). The role of effective mentors in learning to teach. Journal of Teacher Education, 51(2), 102-112.

Farrell, T.S.C. (2007a). Failing the practicum: Narrowing the gap between expectations and reality with reflective practice. TESOL Quartely, 41, 193-201.

Farrell, T.S.C. (2007b). Reflective language teaching: From research to practice. London: Continuum.

Flowerdew, J. (1999). The practicum in L2 teacher education: A Hong Kong case study. TESOL Quarterly, 33, 141-145.

Freeman, D., \& Johnson, K.E. (1998). Reconceptualizing the knowledge-base of language teacher education. TESOL Quarterly, 32, 397-417.

Freeman, D., \& Johnson, K. E. (2004). Readers react ... common misconceptions about the quiet revolution. TESOL Quarterly, 38, 119-127.

Freeman, D., \& Johnson, K.E. (2005). Response to Tarone and Allwright. In D. Tedick (Ed.), Second language teacher education: International perspectives (pp. 25-32). Mahwah, NJ: Earlbaum.

Gebhard, M. (1998). A case for professional development schools. TESOL Quarterly, 32, 501-510.

Grabe, W., Stoller, F.L., \& Tardy, C. (2000). Disciplinary knowledge as a foundation for teacher preparation. In J.K. Hall \& G. Eggington (Eds.), The sociopolitics of English Language teaching (pp. 178-194). Clevedon, UK: Multilingual Matters.

Graham, B. (2006). Conditions for successful field experiences: Perceptions of cooperating teachers. Teaching and Teacher Education, 22, 1118-1129.

Hall Haley, M. (2004). Implications of using case study instruction in a foreign/second language methods course. Foreign Language Annals, 37, 290-300.

Johnson, K.A. (2003). Every experience is a moving force." Identity and growth through mentoring. Teaching and Teacher Education, 19, 787-800. 
Johnson, K.E. (2006). The sociocultural turn and its challenges for second language teacher education. TESOL Quarterly, 40, 235-257.

Johnson, K.E. (2009). Second language teacher education: A sociocultural perspective. New York: Routledge.

Johnson, K.E., \& Golombek, P.R. (2011). The transformative power of narrative in second language teacher education. TESOL Quarterly, 45, 486-509.

Kahn, B. (2001). Portrait of success: Cooperating teachers and the student teaching experience. Action in Teacher Education, 22(4), 48-58.

Koerner, M.E. (1992). The cooperating teacher: An ambivalent participant in student teaching. Journal of Teacher Education, 43, 46-56.

Kornblum, H., \& Garschick, E. (2001). Directory of professional preparation programs in TESOL in the United States and Canada, 1999-2001. Alexandria, VA: TESOL.

Koskela, R., \& Ganser, T. (1998). The cooperating teacher role and career development. Education, 119(1), 106-115.

Lemma, P. (1993). The cooperating teacher as supervisor: A case study. Journal of Curriculum and Supervision, 8, 329-342.

Muchisky, D., \& Yates, R. (2004). The authors respond ... defending the discipline, field, and profession. TESOL Quarterly, 38, 134-140.

Murphy, J.M. (1992). An Etiquette for the non-supervisory observation of L2 classrooms. Foreign Language Annals, 25, 215-223.

Palmer, I.C. (1995, March). Required courses for master's degrees: A nationwide survey. Paper presented at the 29th Annual TESOL Convention, Long Beach, CA.

Phairee, C., Sanitchon, N., Suphanangthong, I., Graham, S., Prompruang, J., de Groot, F.O., \& Hopkins, D. (2008). The teaching practicum in Thailand: Three perspectives. TESOL Quarterly, 42, 655-659.

Richards, J.C. (2008). Growing up with TESOL. English Teaching Forum, 46(1), 2-11.

Richards, J.C., \& Crookes, G. (1988). The practicum in TESOL. TESOL Quarterly, 22, 9-27.

Richards, J.C., \& Farrell, T.S. C. (2011). Practice teaching: A reflective approach. Cambridge, UK: Cambridge University Press.

Richards, J.C., \& Lockhart, C. (1996). Reflective teaching in second language classrooms. Cambridge, UK: Cambridge University Press.

Sinclair, C., Dowson, M., \& Thistleton-Martin, J. (2006). Motivations and profiles of cooperating teachers: Who volunteers and why? Teaching and Teacher Education, 22, 263-279.

Stoynoff, S. (1999). The TESOL practicum: An integrated model in the U.S. TESOL Quarterly, 33, 145-151.

Tarone, E., \& Allwright, D. (2005). Second language teacher learning and student second language learning: Shaping the knowledge base. In D. Tedick (Ed.), Second language teacher education: International perspectives (pp. 5-23). Mahwah, NJ: Earlbaum.

Veal, M.L., \& Rikard, L. (1998). Cooperating teachers' perspectives on the student teaching triad. Journal of Teacher Education, 49, 108-119.

Velez-Rendon, G. (2006). From student to teacher: A successful transition. Foreign Language Annals, 39, 320-333.

Vygotsky, L. (1978). Mind in society: The development of higher psychological processes. Cambridge, MA: Harvard University Press.

Vygotsky, L. (1986). Thought and language. Cambridge, MA: MIT Press.

Wajnryb, R. (1990). Grammar dictation. Oxford, UK: Oxford University Press.

Yates, R., \& Muchisky, D. (2003). On reconceptualizing teacher education. TESOL Quarterly, 37, 135-147. 